\title{
História dos conceitos e história comparada: elementos para um debate
}

Conceptual History and Compared

History: topics for a debate

\section{João Paulo Garrido Pimenta}

Professor no Departamento de

História da Universidade de São Paulo

\section{Resumo}

A proposta deste artigo é discutir algumas das proposições de Guillermo Zermeño Padilla acerca da história do conceito de história na América ibérica entre os séculos XVIII e XIX. Mais especificamente, pretende-se debater algumas das relações entre a história dos conceitos e a chamada "história comparada".

\section{Abstract}

The aim of this article is to highlight topics of debate concerning Guillermo Zermeño Padilla's on the concept of history in Portuguese and Spanish America in the 18th and 19th centuries. More specifically, it analyses some relations between the history of concepts and comparative history.

\section{Palavras-chave}

história das idéias, modernidade, Independência, historiografia, nação, metodologia

\section{Keywords}

history of ideas, modernity, Independence, historiography, nation, methodology 
1

KOSELLECK, Reinhardt. Futuro pasado: para uma semântica de los tiempos históricos. Barcelona: Paidós, 1993. p.287-332 (Modernidad).

2

Todas as citações foram feitas de acordo com a versão original do trabalho de Zermeño, em espanhol.

Por exemplo: HALPERIN DONGHI, Tulio. Reforma y disolución de los impérios ibéricos, 1750-1850. Madri: Alianza, 1985

Grifo meu
Em meio às mais consistentes elaborações teóricas acerca daquilo que muitos autores costumam chamar, de forma razoavelmente consensual, como "história dos conceitos", são freqüentes as referências à possibilidade ou necessidade, imbuídas nesse campo de reflexão e análise, de recorrência a abordagens comparativas. Estudar conceitos, tomados historicamente como parâmetros dinâmicos de reprodução da vida social e como portadores de densos conteúdos relacionados a formas de representação e transformação do mundo, pode implicar, em alguma medida, comparar conceitos. Sobretudo quando estes se relacionam com contextos históricos amplos e abrangentes, não redutiveis a fronteiras nacionais - nenhuma história pretensamente "nacional" em realidade o é - ou a outras formas de limitação e isolamento.

Alguns desses contextos se inscrevem em meio aquele laboratório de experimentação de que se valeu Reinhardt Koselleck para testar suas primeiras hipóteses e formulações teóricas acerca dessa história dos conceitos da qual ele é um dos grandes, se não o maior, representante. 0 mundo ocidental entre, aproximadamente, 1750 e 1850, observaria um conjunto de profundas transformações que se caracterizaria pelo advento progressivo de uma nova forma de relação social com o tempo; uma forma até então inédita, multifacetada, mais tendencial do que absoluta, e designada como "modernidade".1 Com a elaboração de Koselleck, a modernidade se constitui não apenas em um pano de fundo geral a partir do qual se desenrola uma grande variedade de fenômenos observáveis naquele tempo-espaço, mas igualmente em uma ferramenta analítica capaz de oferecer sentido a tais fenômenos.

Assumidamente desdobrando tais proposições, "Historia, experiencia y modernidad en Iberoamérica (1750-1850)"2 de Guillermo Zermeño Padilla avança substancialmente no entendimento de alguns desses fenômenos, em contextos não diretamente tratados pelo historiador alemão e até o momento pouco merecedores da atenção dos estudiosos da história dos conceitos em geral: o mundo iberoamericano entre dois momentos cruciais de seu desenvolvimento que, em termos já consagrados, ${ }^{3}$ podem ser tidos como indicativos aproximados da crise dos impérios ibéricos e da consolidação dos Estados nacionais dela resultantes. Nas palavras de Zermeño, trata-se de um esforço por apresentar "una síntesis comparativa de la evolución del término historia y su relación con la formación de un nuevo espacio de experiencia caracterizado como 'moderno'"; o que implicaria, ao término desse esforço preliminar, um intento de "comparabilidad entre diversos tipos de experiencias de la historia sostenidas en lenguajes y culturas limitrofes". 4

Nesta prática especifica de uma história dos conceitos, portanto, Zermeño indissocia o desvendar de uma realidade social - cuja dinâmica se revela nas transformações de conteúdos dos quais o termo história é portador - de uma comparação entre diferentes experiências históricas próximas e similares que, em realidade, parecem compor uma única experiência. Em suas palavras, "una experiencia global que atraviesa tanto a paises metropolitanos como a las provincias imperiales", relacionada com o processo de "interiorización de un nuevo tipo de experiencia no reducible a individuos aislados, sino a la sociedad en conjunto", tendo como uma de suas caracteristicas a capacidade de "sincronizar lo que hasta entonces parecía que no tenía que ver una cosa con la otra". A chave para a comparação entre seus elementos - isto é, entre os variados adventos específicos da modernidade no mundo iberoamericano - seria dada pelas categorias koselleckianas 
KOCKA, Jürgen. Comparison and Beyond. History and Theory, n.42, p.39, febr. 2003 de "espaço de experiência" e "horizonte de expectativa", pelas presentes relações entre passado e futuro. Na medida em que manifestações de percepções e concepções do tempo histórico - bem como suas materializações em diversos níveis da vida social - seriam sempre experiências históricas únicas, a comparação, por meio de tais categorias, pressuporia a fertilidade da abordagem de contextos variados que compõe um só, e do cotejamento de diferentes manifestações que resultam em um fenômeno comum.

Assim, a história dos conceitos praticada por Zermeño carrega consigo uma proposta de recorrência à comparação como método não apenas válido, mas necessário de análise. A questão é importante: a história dos conceitos nem sempre é, obrigatoriamente, uma história comparada, e quando o é, não estou totalmente seguro acerca de sua fundamentação enquanto tal. Minha inquietação reside na constatação de que embora a segunda venha sendo objeto de muita reflexão em diversas áreas das ciências humanas desde meados do século XX - sobretudo da História e da Sociologia - a história dos conceitos não parece ainda ter sido capaz de oferecer elementos de uma teoria renovada em torno do problema; nesse sentido, parece-me ainda escasso o diálogo entre práticas de história dos conceitos e de história comparada, pensadas enquanto métodos de perquirição da realidade dotados de trajetórias epistemológicas específicas.

Minha proposta reside em oferecer, muito brevemente e a partir do artigo de Zermeño, elementos de reflexão em torno do seguinte problema: como se comporta a dimensão comparativa inerente à história dos conceitos - ou pelo menos desse modo concebida - diante de uma reflexão mais ampliada acerca da história comparada enquanto método de análise? De modo mais preciso, tal problema se desdobra em dois: 1) o do conceito de história em sua relação com a modernidade no mundo iberoamericano, entre 1750 e 1850, à luz de uma comparação entre diferentes desenvolvimentos específicos do conceito; 2) o do processo iberoamericano de crise do Antigo Regime e de formação dos Estados nacionais, e os avanços e limites que são trazidos à sua compreensão, via história dos conceitos e história do conceito de história, por uma reflexão ampliada da comparação como método.

Em primeiro lugar, devo reconhecer na história comparada a possibilidade de um método útil. Não como ponto de partida ou de chegada, mas como recurso meramente circunstancial e limitado, a comparação em história, nas palavras de Jürgen Kocka, "ajuda a identificar questões e a esclarecer perfis de casos singulares. Ela é indispensável para explicações causais e suas críticas [e] ajuda a criar um clima menos provinciano à investigação histórica". 5 Como todo e qualquer método, oferece também sérios riscos quando tomado a priori, como fundamento próprio da investigação, ou quando não obedece às suas contingências e imposições.

No caso do tempo-espaço em questão, penso que a comparação oferece o risco básico de isolar e reificar unidades históricas de análise, retirando-as de um contexto geral que Ihes confere significado. 0 mundo iberoamericano entre 1750 e 1850 é todo diversidade; na mesma medida, é um campo de trocas, influências e determinações reciprocas que frequentemente encontra-se esquartejado pelo historiador. Como é assaz sabido, o reformismo imperial ibérico incide sobre realidades complexas em termos de reconhecimento de que, em meados do século XVIII, Portugal e Espanha perdiam a competição colonial, ao passo em que mantinham territórios cuja exploração racionalizada poderia oferecer condições propícias, se não à superação, ao menos à atenuação de tal condição. 0 contexto geral, 
Trabalhei a questão em: PIMENTA, João Paulo G. Brasil y las independências de Hispanoamérica. Castelló de la Plana, Universitat Jaume I, 2006.

McMICHAEL, Philip. Incorporating Comparison Within a World-Historical Perspective: an Alternative Comparative Method. American Sociological Review, n.55, p.385-397, jun.1990.

KOSELLECK, Reinhardt. Futuro pasado: para uma semântica de los tiempos históricos. Barcelona: Paidós, 1993. p.41-66 (Historia magistra vitae). portanto, é comum. Com as reformas, as especificidades ibéricas não apenas são mantidas, mas em muitos casos acirradas a ponto de configurarem fissuras e tensões em panoramas até então razoavelmente coesos e harmônicos em termos de manutenção dos impérios como unidades complexas. 0 auge da crise, entre 1807-1808, resultando em situações imediatas diametralmente opostas nos dois impérios, criará não apenas as condições para a abertura, igualmente diferenciada, dos processos de independência nas Américas portuguesa e espanhola, como os próprios padrões da doravante determinação reciproca entre ambos os movimentos. ${ }^{6}$ Em última instância, podemos afirmar que é aqui que se definem as condições essenciais de singularização das experiências "modernas" nos espaços americanos que, em pouco tempo, resultarão na formação de novos estados e nações, bem como na formulação conceitual de um novo tempo vivido, para a qual o conceito de história é central.

Desse modo, se o reconhecimento de uma unidade histórica geral e heterogênea não necessariamente exclui a possibilidade de dela serem retiradas e cotejadas unidades de comparação, ${ }^{7}$ a aplicação de critérios "nacionais" ao estudo de realidades específicas em meio ao contexto iberoamericano entre 1750 e 1850 se constitui em evidente anacronismo. Afinal, se a singularização das experiências históricas em meio a tal contexto é resultado, em muitas medidas, de uma dinâmica de interações recíprocas, em termos absolutos ela é fim, é resultado de um processo que, portanto, não autoriza avaliações retrospectivas. Nesse ponto, a história dos conceitos, mais especificamente a do conceito de história, se mostra poderosa. A modernidade, apreciada como uma experiência geral de singularização de articulações entre passado e futuro, de experiências históricas específicas tornadas definitivas em meio a um movimento de progressiva perda do caráter funcional do estudo do passado - a história magistra vita $^{8}$-, pode, como bem aponta Zermeño, balizar a compreensão das diferenças reciprocas entre as diferentes modalidades de desenvolvimento do conceito. Nesse sentido, cada "história nacional" surgida no mundo iberoamericano entre 1750 e 1850 representa manifestação de um movimento geral, cuja desconsideração, da parte dos historiadores, resulta em uma postura inaceitável: uma "nacionalização" das histórias nacionais, portanto a reificação de seu objeto de estudo e a reiteração de dimensões míticoideológicas a ele inerentes. No sentido oposto, uma "desnacionalização" das histórias nacionais respeitaria a complexidade do processo histórico geral que thes confere significado. 0 que implicaria que, enquanto história comparada, a história dos conceitos deve ser uma história não-nacional.

Isso nos recoloca diante de um dos problemas centrais da utilização não apenas da comparação, mas de todo e qualquer método de análise histórica: como explicar o passado respeitando as múltiplas abrangências, diversidades, temporalidades e contradições do real. Assim, se a proposta de Zermeño, com base no conceito de história, nos mostra efetivamente como a história dos conceitos pode reforçar a historicização das singularizações nacionais iberoamericanas em meio a um processo geral, o problema da reconstituição desse processo à luz de sua diversidade permanece em aberto. Em suas palavras, "en vistas al examen de los diversos procesos examinados sobre la evolución del concepto Historia en lberoamérica, lo más significativo será poder mostrar, de un lado las semejanzas (que pueden expresarse en un vocabulario compartido) y, del otro, las posibles diferencias que permitirán 
especificar la singularidad de cada experiencia. Ese ser distinto dentro de lo semejante, sería lo decisivo en esta investigación compartida".

Concluo matizando uma afirmação central no texto de Zermeño, a de que "en general habria coincidencia en que este cambio tuvo lugar en el medio lberoamericano entre 1808 y 1823, propiciado no tanto por un movimiento intelectual como por movimientos sociales y politicos que originaron la desarticulación del imperio español y portugués. Así, los cambios políticos son los que movilizan la transformación semántica de la historia, sin que exista de por medio una elaboración intelectual previa". Trata-se de uma idéia forte e, creio, sob muitos ângulos válida. Contudo, sendo o mundo iberoamericano entre 1750 e 1850 um laboratório de trocas dinâmicas, das quais resultam soluções políticas inovadoras, não me parece conveniente uma estrita separação entre "movimento intelectual" e "movimentos sociais e políticos" que, no meu entender, encontra-se diluida - se não inteiramente eliminada - pela categoria de "experiência". Por exemplo: as leituras americanas de autores influentes como por exemplo Raynal, Robertson, De Pradt, Viscardo Guzmán e Hipólito da Costa, feitas em paralelo com autores clássicos ou iluministas, são, simultaneamente, movimentos intelectuais e politicos; inserem-se em tradições intelectuais que são ao mesmo tempo européias e americanas, materializam concepções de passado e de futuro e delimitam campos e padrões de atuação política. Do mesmo modo, acontecimentos como as rebeliões indígenas do Peru, as invasões britânicas ao Prata, as "insurgências" mexicanas de Hidalgo e Morelos, a transferência da Corte portuguesa para o Brasil ou a Revolução de Pernambuco, se fazem mais ou menos passados, mais ou menos presentes no cenário iberoamericano ao lado de outros dos séculos anteriores, a depender dos diferentes contextos por eles transformados e pelas diferentes leituras que deles são feitas. Como resultado geral, em quaisquer casos, uma "consciência coletiva do singular", fundamental na criação de condições de projeção de um mundo colonial sem a metrópole, bem como de mundos nacionais americanos distintos uns dos outros. Do mesmo modo a transformação do conceito história, causa e conseqüência dessa transformação geral.

Na América ibérica, entre 1750 e 1850 a circulação, compartilhamento e embate das diferenças propiciadas pela singularização de experiências históricas típica da "modernidade" permitiram que não apenas do passado, mas também do presente, se extraissem ensinamentos. E se tais ensinamentos, por um lado, denunciam a perda de operacionalidade da história, mestra da vida, de outro parecem impor limites a essa perda. É como se o passado ainda ensinasse algo, mas cada vez mais um passado próximo, que toma o lugar até então ocupado pelo passado distante. 0 tempo curto se sobressai ao tempo longo, o presente se impõe e o tempo histórico se acelera. Assim, em meio a algo que chamaria de um "espaço de experiência revolucionário moderno", outros "espaços de experiência" menores a ele articulados mas dele se autonomizando, se tornam mais densos e determinantes do futuro, um futuro que não mais se repete. Ao pressupor uma dialética entre geral e particular, entre singular e coletivo, a dimensão comparativa de uma história dos conceitos do mundo iberoamericano entre 1750 e 1850 parece oferecer, assim, bases teóricas nada despreziveis para a compreensão de um processo geral cuja complexidade escapa a uma simples somatória da diversidade a ele inerente, uma diversidade por ele recriada.

Recebido para publicação em março de 2008 